\title{
Just married: the synergy between feminist criminology and the Tripartite Cybercrime Framework
}

THE FINAL DRAFT VERSION. The Version of Record can be found here: https://doi.org/10.1111/issj.12201

\begin{abstract}
: -
This article is a theoretical treatment of feminist epistemology of crime, which advocates the centrality of gender as a theoretical starting point for the investigating of digital crimes. It does so by exploring the synergy between the feminist perspectives and the Tripartite Cybercrime Framework (TCF) (which argues that three possible factors motivate cybercrimes - socioeconomic, psychosocial, and geopolitical) to critique mainstream criminology and the meaning of the term "cybercrime". Additionally, the article examines gender gaps in online harassment, cyber-bullying, cyber-fraud, revenge porn, and cyber-stalking to demonstrate that who is victimised, why, and to what effect are the critical starting points for the analysis of the connections between gender and crimes. In turn, it uses the lens of intersectionality to acknowledge that, while conceptions of gender and crime interact, they intersect with other categories (e.g., sexuality) to provide additional layers of explanation. To nuance the utilitarian value of the synergy between the TCF and the feminist perspectives, the focus shifts to a recent case study (which compared socioeconomic and psychosocial cybercrimes). The article concludes that, while online and offline lives are inextricably intertwined, the victimisations in psychosocial cybercrimes may be more gendered than in socioeconomic cybercrimes. These contributions align the TCF to the feminist epistemology of crime in their attempt to move gender analysis of digital crimes "from margin to centre".
\end{abstract}

\section{Cite article as:}

Lazarus, S. (2019). Just married: the synergy between feminist criminology and the Tripartite Cybercrime Framework. International Social Science Journal, 69(231), 15-33. 


\section{Introduction}

This article sets out to discuss the value of feminist theory in understanding digital crimes. Almost acentury ago, Freud (1927) had reminded us in his analysis of "civilisation and its discontents" that technology is not only responsible for our advancement, but also for our "misery". It is indisputable that the critical aspects of costs and benefits associated with the use of information and communication technologies (ICTs) are different for men and women (Al Izki and Weir 2015; McGerty 2000; Mumporeze and Prieler 2017). Indeed, gender issues in cyberspace are reflections of their antecedents in society (Baym and boyd 2012; Braithwaite 2014; Jane 2016a,b); who is victimised, why, and to what effect are the critical starting points for the analysis of gender and crimes (Burgess-Proctor 2006; Cook 2016; Eagly 2016). However, these gen- der issues are obscured through the definitional lens of "cybercrime" and mainstream criminology theories. While mainstream criminologists have broadly taken for granted that men (and boys) predominate in traditional crimes as perpetrators, most generalisable criminological research on digital crimes is a mere reflection of the prevailing criminology theories of traditional crimes (Cook 2016; Potter 2015; Sharp 2015). This article is a plea for greater expansion of our analysis of gender issues in all areas of cyber criminology.

For Jaishankar $(2007,2011)$, "cyber criminology" is the notion that the causations, experiences, consequences, and patterns of crimes that are relevant in the physical space concurrently impact in the cyberspace and vice versa (see also Lazarus 2019; Powell et al. 2018). By the same token, in most investigations of crime, the polarisation of the real world and the virtual world obstructs the understanding of gender dynamics online (Braithwaite 2014; Eckert 2018; McGerty 2000; Morahan-Martin 2000a; Vasilescu et al. 2012). Indeed, "nobody lives only in cyberspace" (McGerty 2000, p.895). "Life online is a mere extension of life offline" since socially constructed cues on gender offline are concurrently impactful in the digital realm (Morahan-Martin 2000a, p.689). Using these ideas as a starting point, this paper asks: do structured gender relations retain their efficacy in online contexts? Do gender forces in society influence online behaviours and experiences? Doing so is prompted by two central motives: (a) to critique mainstream criminology and advocate the centrality of gender as a theoretical entry point for the investigating of all aspects of cyber criminology; (b) to critique the meaning of the term "cybercrime" and build a synergy between the feminist epistemology of crime and a conceptual cybercrime framework. The underlying impetus is that it is of the utmost importance for the umbrella term "cybercrime" and other typologies and theories that inhibit a more critical examination of gender dimension of crime to be revisited and redefined because they have significant consequences for interpretations. To illustrate that online behaviours and attitudes are mere extensions of offline social processes and relationships, this article will chronologically provide an overview of gender gaps in a range of digital crimes (online harassment, cyberbullying, cyber- fraud, revenge porn, and cyber-stalking). It will also use a recent comparison of digital forms of crime including digital piracy, i.e., Donner's (2016) work, as a case study to illustrate how mainstream criminology (and the term cybercrime) has, for example, undermined the feminist epistemology of crime. 


\section{Theoretical guidance}

\subsection{Feminist criminology perspectives}

One way to begin understanding feminist criminology is to examine how conceptions of gender and crime interact. Feminist criminology perspectives ${ }^{1}$ or the feminist epistemology of crime advocate a more critical examination of gender issues regarding multiple social life experiences such as crime and justice (Braithwaite 1989; BurgessProctor 2006; Eagly 2016; Sabon 2016). Feminist criminology perspectives are not simply the study of crimes committed by women, nor are they just the study of women and crime (Naegler and Salman 2016; Sharp 2015). The feminist epistemology of crime explicitly takes into account the unequal power of boys/men and girls/women in its approach to the study of crime and gender (Lynch 2016; Naegler and Salman 2016). Many scholars have already noted that gender is situationally accomplished, socially constructed, and culturally performative, and its persistence as a significant factor in real-life experiences is remarkable (Agboola and Rabe 2018; Connell and Messerschmidt 2005; Mumporeze and Prieler 2017; Oakley 2018; Sabon 2016; Schiebinger 2000; West and Zimmerman 1987; Wood and Eagly 2010). Equally, this article, like many scholarly articles before it (e.g., Burgess-Proctor 2006; Dean and Platt 2016; Potter 2015), acknowledges that gender intersects with multiple axes of social (dis)advantages such as age, class, race, and sexuality: "[T]o advance an understanding of gender, crime, and justice, feminist criminologists must examine [these] linkages between inequality and crime using an intersectional theoretical framework" (BurgessProctor 2006, p.28).

By the same token, feminist criminologists must examine these linkages in society that extend to cyberspace through the lens of digital intersectionality (Tynes, Schuschke and Noble 2016). Indeed, the multidisciplinary field of internet studies (e.g., cyber criminology, or digital criminology, computer-mediated communications, cyberpsychology) needs theoretical and methodological approaches that facilitate a more critical examination of the uneven power relations embedded in these intersections that exist in technological spaces (Jane 2016a; Tynes et al. 2016). However, while the article acknowledges that the lens of intersectionality is a significant paradigm in feminist scholarship, it admits that the intersections of the multiple categories involved are many and complex. This article, therefore, will mostly focus on gender and crime connections due to its limited scope. Equally, a core tenet of feminist criminology seeks "to expand criminological theorising about gender and to make gender a central theoretical starting point for theorising about crime" (Lynch 2016, p.3). In particular, "feminist criminology has been largely motivated by the acknowledgement that gendered analyses of crime are vitally important to the field and that sexism influences social life in ways that are nuanced, complex, and enduring" (Cook 2016, p.335).

Building on these ideas, this paper aims to contest the definitional rigidity of the umbrella term (i.e., cybercrime). In a similar vein to feminist criminology, mutually constitutive categories shape people's identities, experiences, and perceptions of all aspects of life, both tangible and intangible (Lynch 2016; Sabon 2016; Schiebinger 2000). Both offenders and victims possess some commonalities, and one of the most salient of these is gender (Hutchings and Chua 2017; Watts et al. 2017). Arguably, as McGerty (2000), 
Eklund (2011), Lazarus (2019), and Vasilescu et al. (2012) pointed out, offline and online contexts are not separate entities with a clearly defined boundary, because people can never be online without being offline too. For example, gender practices and patterns in society continue to thrive in new media (Baym and boyd 2012), whereas "online abuse of women is not fully recognised as entangling online and offline communications" (Eckert 2018, p.1282). Examining gender differences in the virtual world prompts one to consider how cultural nuances inhibit and promote behaviour that, in turn, could shape a person's criminal or law-abiding social actions (Lazarus and Okolorie 2019). Arguably, examining the gender disparities in cybercrime types is crucial to critiquing mainstream criminology theories as well as the term "cybercrime".

\subsection{Feminist critique of mainstream criminology}

Mainstream criminological theories claim to offer generalisable explanations of criminal offending, whereas they have, to a large extent, taken for granted the predominance of men (and boys) in offending (Cook 2016; Daly and Chesney-Lind 1988; Potter 2015). This is because most researchers follow theory as believers follow the- ology (Rimer 1997). Similarly, according to feminist criminology perspectives, most mainstream criminology theories $^{2}$ have missed critical opportunities necessary to advance our understanding of gender and crime (Cook 2016; hooks [1984] 2000; Sharp 2015). Prominent among these theories is "A General Theory of Crime", which argues that, while low self-control has a direct and causal link to all offending, "men are always and everywhere more likely than women to commit criminal acts" (Gottfredson and Hirschi 1990, p.143). The rationale for using this theory as an example acknowledges its substantial influence in criminology and related disciplines. Indeed, as Cook (2016) observed, it has attracted enormous central funding for doctoral training and consequently served as critical theoretical guidance for many doctoral projects in criminology. In particular, according to Cook's (2016) assessment, A General Theory of Crime is closely associated with over 177,000 academic published articles and 57 books. It has not only inspired many academic publications, but it has also extended the conception of crimes beyond the legalistic definition to include "acts of force or fraud undertaken in pursuit of pleasure" (Gottfredson and Hirschi 1990, p.15), which is one of its fundamental contributions.

However, by failing to closely examine gender as an analytical framework, it has ignored gender as a critical source of social (dis)advantage, ${ }^{3}$ which influences patterns of crime and victimhood (Braithwaite 1989; Potter 2015). As Geis (2000, p.40) rightly asked: "how can the general theory of crime incorporate the uncounted number of criminal abortions undergone by women before Roe v. Wade in 1973 legalised the procedure?" Indeed, it would be a stretch to maintain that the presence of low self-control explains the actions of women who have opted for illegal abortions (Geis 2000). Debatably, Gottfredson and Hirschi (1990) failed to see that self-control contains "unacknowledged value assumptions" (Geis 2000) and involves socioeconomic and cultural dynamics (Potter 2015). For example, research in many nations, such as Puerto Rico (Maldonado-Molina et al. 2009), Japan (Chen et al. 2010), Ghana (Boakye 2013), Korea (Bae 2017), and Nigeria (Ibrahim 2017), illustrates that this is so. These authors highlight that self-control is not immune to socio-cultural assumptions and socially constructed cues (e.g., gender nuances), which vary across cultures. 
To ignore socially constructed cues such as gendered nuances not only undermines the centrality of these nuances as conceptual entry points for examining crimes but has enduring real-life consequences in academia. For example, as Sharp (2015,) succinctly noted, generations after generations of students are unaware of feminist criminology and its contributions. They in turn teach their own students mainstream theories, with little, if any, reflection on more explicitly feminist approaches. It is also conceivable that these "generations after generations of students" would use mainstream theories to examine new forms of crimes in digitalised societies (digital crimes) at the expense of the feminist epistemology of crime. Arguably, mainstream criminology theories (e.g., A General Theory of Crime) and their generational subscribers not only perpetuate androcentric conceptions within criminology (Potter 2015), but they dismiss volumes of criminological research documenting that gender is acrucial index factor in crime and victimisation (Cook 2016; Eagly 2016).

In a nutshell, most mainstream criminology theories (e.g., A General Theory of Crime) have missed critical opportunities necessary to advance our understanding of gender and crime (Cook 2016; hooks [1984] 2000; Sharp 2015). That is, the real world and the virtual one are not independent spaces and internet users are rooted in both worlds simultaneously (Braithwaite 2014; Eckert 2018; Eklund 2011; Vasilescu et al. 2012). To draw attention to these issues would encourage rather than dis- courage "corporations and governments agencies in addressing misogyny issues in the cyberspace" (Jane 2016a, p.292). Therefore, this paper is a theoretical endeavour that explores the synergy between feminist criminology and a conceptual cybercrime framework to argue for the centrality of gender as a conceptual starting point for investigating the socioeconomic and psychosocial impacts of ICTs. The underlying impetus is that most mainstream criminological theories sidetrack gender nuances and impose their mainstream image upon the feminist epistemology of crime. Equally, most generalisable cybercrime typologies limit the windows of opportunity to examine gender differences concerning a range of digital crimes and their motivations. This current paper sets out to move gender analysis of digital crimes, in hooks' ([1984] 2000) term, "from margin to centre".

\section{The meaning of cybercrime and ambiguities}

\subsection{An umbrella term anddual typologies}

Cybercrime refers to any criminal activity carried out through the use of ICTs and the internet (e.g., Gordon and Ford 2006; Richardson and Gilmour 2015). It has been defined in different jurisdictions and by many scholars (e.g., Gordon and Ford 2006; Hutchings and Chua 2017) and security agencies (e.g., National Crime Agency 2017; Norton 2015) to mean slightly different things. However, the most consistent idea is that the term "cybercrime" is an umbrella word for a wide spectrum of digital crimes such as hacking, cyber espionage, cyber-stalking, cyber fraud, cyber vandalism, online revenge pornography, and the distribution of computer viruses (Donner et al. 2015; Ibrahim 2016; Kirillova et al. 2017; Yar2017). The term "cybercrime", on the one hand, is overly broad, and on the other it is rigid. By implication, it is resistant to change because it is "loosely" used in everyday parlance as a simple "acronym" for all forms of crimes on the internet. 


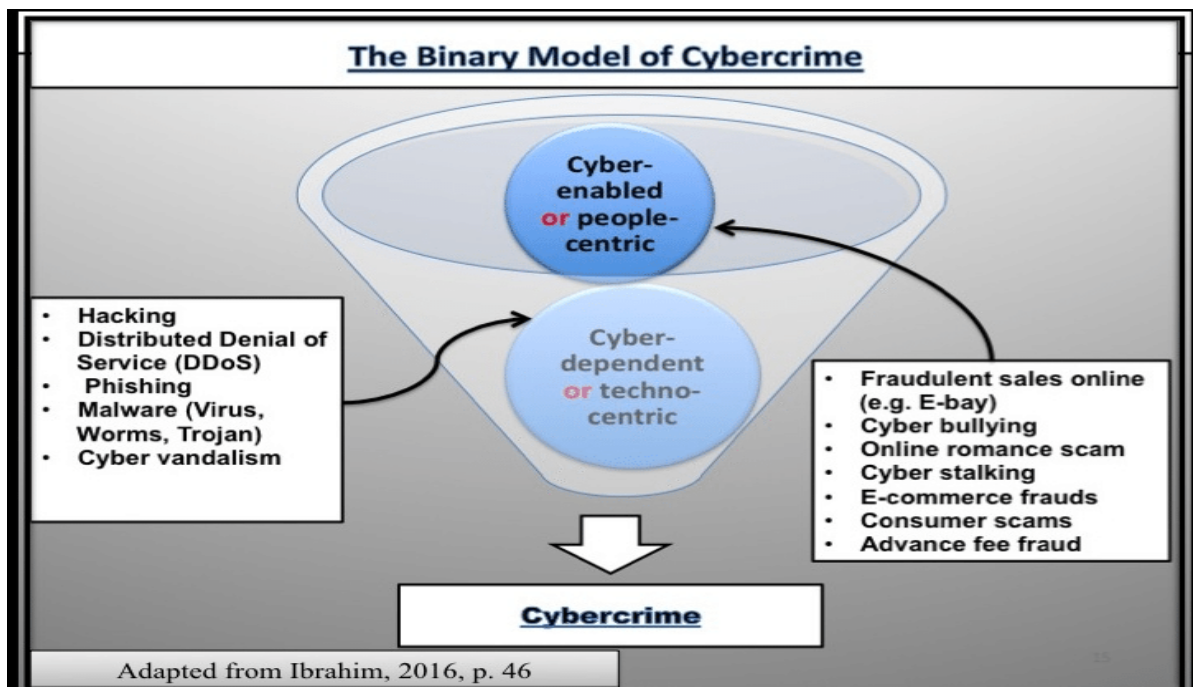

Consequently, there is a fairly clear pattern to suggest that in using the term "cybercrime" as agiven, multitudes of researchers "clump together" a wide spectrum of digital crimes with arbitrary attributes (e.g., Bidgoli and Grossklags 2016; Hill and Marion 2016; Sabillon et al. 2016). This paper attempts to highlight the analytic consequences of this homogenisation on gender issues. Many other scholars (e.g., Gordon and Ford 2006; McGuire and Dowling 2013; Rokven et al. 2018) have used the terms "cyber-enabled crimes", "people- centric cybercrimes" or "cyber-dependent crimes" to represent a range of crimes, regardless of the ambiguity the terms embody. As illustrated in Figure 1, cyberenabled crimes or people-centric cybercrimes encompass all crimes that existed before the advent of ICTs and that can now be digitalised, whereas cyber-dependent crimes or techno- centric cybercrime comprise crimes or behaviours that were made possible through the development of ICTs.

The cyber-enabled/people-centric category encompasses a broad spectrum of digital crimes with arbitrary attributes, where they obscure the meaning of each cybercrime type they represent, which is problematic (Ibrahim 2016). Cyber- enabled or people-centric cybercrime includes a wide variety of criminal activities ranging from the illegal downloading of music (digital piracy) to revenge pornography. Indeed, many of the digital crimes that some researchers (Gordon and Ford 2006; McGuire and Dowling 2013) forced under one rubric (i.e., cyber-enabled or people-centric) appear distinctive enough to require other kinds of explanations if we expect to be able to understand them, their effects, and their occurrence with some degree of consistency - other than that they are "cyber-enabled".

For example, cyberbullying and fraudulent sales on eBay involve different motivations, victim- perpetrator gains/losses and victim-perpetrator relationship/dynamics, as shown 
in Table 1 (for a fuller critique of varying cybercrime classifications, see Ibrahim 2016). This article builds on Ibrahim's (2016) idea that social/contextual factors apply online as they do offline and aims to advance it by explicitly taking into account the perspectives of feminist criminology. Accordingly, given that such crimes (i.e., cyberbullying and fraudulent sales on eBay) are qualitatively different, this current endeavour sets out to highlight that these umbrella terms (e.g., cybercrime or cyber-enabled crimes) have, by implication, debilitated the examination of gender comparison between cyberbullying and fraudulent activities. As regards cyberbullying and cyber-fraud, the victimperpetrator motives and gains and losses are not the same, as shown in Table 1. In other words, the homogenisation of crimes with different core attributes not only inhibits the policing of these crimes (Rosenbach and Belk 2012) but also debilitates a more critical examination of gender psychology and victimisations in a wide spectrum of digital crimes.

Indeed, online behaviours and attitudes are extensions of offline social processes and relationships (Al Izki and Weir 2015; Citron 2014; Lazarus 2019). Empirical evidence from many cultures ${ }^{4}$ such as Sweden (Priebe and Svedin 2012), Rwanda (Mumporeze and Prieler 2017), Australia (Hutchings and Chua 2017), Nigeria (Lazarus 2018), Thailand (Ojanen et al. 2015), Canada (Cunning- ham et al. 2015), Korea (Bae 2017), Germany, Switzerland, the United Kingdom, and the United States (Eckert 2018) demonstrate that this is so. "Differences between men's and women's experiences of the internet are linked to broader questions of gender in society, and therefore gender issues in cyberspace are likely to persist as long as they exist offline" (Sherman et al. 2000, p.893; see also Jane 2016a; Eckert 2018). Anchoring on the above insights, while "understanding gender inevitably involves comparisons, such comparisons are essential to developing an understanding of the psychology of gender" (Eagly 2016, p.286) and victimisations. Conceptually, this paper sets out to advocate the centrality of gender as a starting point for investigating various types of digital crimes.

\subsection{The Tripartite Cybercrime Framework (TCF)}

Social and contextual factors are a resource for understanding the connections between gender and digital crimes (Lazarus and Okolorie 2019). A nascent typology, and one better suited to investigating the linkages between gender and digital crimes, is the Tripartite Cyber- crime Framework (TCF) proposed by Ibrahim (2016). According to the TCF, cybercrime can be divided into three broad motivational parts: socioeconomic; psychosocial; and geopolitical. Socioeconomic cybercrime can be defined as the computer- and/or internet-mediated acquisition of financial benefits by false pretense, impersonation, counterfeiting, forgery, or any other fraudulent representation of facts such as online fraud, credit card fraud, romance scams, and e-embezzlement.

Psychosocial cybercrime refers to digital crimes that are primarily psychologically driven, such as cyber-stalking, cyberbullying, and cyber- harassment, whereas geopolitical cybercrimes can be defined as those cybercrimes that are fundamentally political in nature and involve agents of the state and/or industrial representatives, e.g., cyber espionage. The TCF is more robust than the term "cybercrime" and other classifications mentioned in Figure 1 in dealing with the complexities of numerous varieties of cybercrime types. Because structured gender relations retain their efficacy 
in online contexts, this research will particularly benefit from the TCF. The lens of binary classifications and that of the buzzword "cybercrime" (discussed above) are ill-equipped, for example, to differentiate between the psychosocial and socioeconomic categories. Unlike these classifications (e.g., the dual groups), the TCF acknowledges the importance of different motivations behind criminal behaviours. These characteristics in them- selves bring the TCF closer to the feminist epistemology of crime than other typologies mentioned.

TABLE 1. Perpetrators' benefit and victims' losses

\begin{tabular}{|l|l|l|l|}
\hline Attacker/Attacked & Socioeconomic & Psychosocial & Geopolitical \\
\hline $\begin{array}{l}\text { Perpetrator } \\
\text { (primary benefit) }\end{array}$ & Economic gain & $\begin{array}{l}\text { Psychological } \\
\text { gain }\end{array}$ & $\begin{array}{l}\text { Geopolitical, economic } \\
\text { \& psychological gain }\end{array}$ \\
\hline $\begin{array}{l}\text { Victim } \\
\text { (primary loss) }\end{array}$ & Economic loss & Psychological loss & $\begin{array}{l}\text { Geopolitical, economic } \\
\text { \& psychological loss }\end{array}$ \\
\hline $\begin{array}{l}\text { Perpetrator } \\
\text { (secondary benefit) }\end{array}$ & $\begin{array}{l}\text { Psychological } \\
\text { gain }\end{array}$ & Economic gain & $\begin{array}{l}\text { Geopolitical, economic } \\
\text { \& psychological gain }\end{array}$ \\
\hline $\begin{array}{l}\text { Victim } \\
\text { (secondary loss) }\end{array}$ & $\begin{array}{l}\text { Psychological } \\
\text { loss }\end{array}$ & Economic loss & $\begin{array}{l}\text { Geopolitical, economic } \\
\text { \& psychological loss }\end{array}$ \\
\hline
\end{tabular}

\subsection{The Tripartite Cybercrime Framework (TCF) and feminist criminology connections}

There is an implicit overlap between the TCF and the feminist epistemology of crime. The TCF is rooted in social and cultural nuances of crime and victimisation. It is essentially based on the premise that perpetrators and victims of a wide spectrum of digital crimes have a unique relationship and that this relationship is fundamentally based on the perpetrators' primary motivations and benefits and the victims' primary losses, as mentioned and shown in Table 1 (adapted from Ibrahim 2016, p.47). Given that, for example, online abuse disproportionately affects women (e.g., Citron 2014) and "online abuse of women is not fully recognised as entangling online and offline communication" (Eckert 2018, p.1282), conceptually, the TCF offers avenues to situate gender at the core of crime analysis. Theoretically, locating gender at the core of crime investigation acknowledges the sources of social advantage and disadvantage in society. While sources of social advantage and disadvantage are related to patterns of offending and victimisation (Näsi et al. 2015; Newburn 2016), gender is one of the critical sources of social advantage and disadvantage in society (Fogiel-Bijaoui 2016; Lazarus el al. 2017; Tynes et al. 2016). For example, unlike men, deprived Israeli mothers are forced to pay rents in the coin of sexual services (Lavee and Benjamin 2017). On the flipside, women's possession of high economic power can have detrimental effects on their marriages and their chances of remarriage in Nigeria (Lazarus et al. 2017). 
The critical point here is that gender inequality itself structures these types of women's experiences in Israel and Nigeria mentioned above. Indeed, gender is a central source of social disadvantages that positions these women between exclusion and belonging. Relatedly, for the TCF, it is conceivable that gender comprises the everyday reality of crime and victimisation, especially the perpetrator-victim gains and losses. Similarly, for the feminist epistemology of crime, the analysis of gender and crime begins with understanding who become victims and why and what results ensue (Cook 2016; Eagly 2016; Potter 2015). For example, focusing primarily on cyber-hate, Jane (2016b, p.10) observed that "women are being attacked online more often, more severely, and in far more violently sexualised ways than men" (see also Eckert 2018). The mismatch between men's and women's involvement in, and experiences of, internet crime are linked to broader questions of gender in society (Citron 2014; Hutchings and Chua 2017).

Additionally, for feminist perspectives, con- textual lenses are invaluable tools of analysis. For example, Jones' (2018) analysis of international interoperability outlined the long histories of the different cultural and legal contexts involving many nations, e.g., European countries and the United States. Similarly, for the TCF, "jurisdictional cultures and nuances apply online as they do offline" (Ibrahim 2016, p.44). Indeed, while the TCF takes into account the cultural and contextual nuances of crime, it acknowledges the importance of the motivation-based relationship between offenders and victims in its classification of cybercrime. Relatedly, feminist criminology explicitly takes into account the unequal power of boys/men and girls/women in its approach to the study of crime and justice.

\subsection{Contrasting the socioeconomic and psychosocial cybercrimes types}

This current endeavour operationalises this frame- work (TCF), which comprises three components. However, it focuses on only two parts (i.e., the socioeconomic and psychosocial cybercrime groups) to contrast the nature of their attributes. This strategy resonates with the view that the motivations, victimisations, and relational processes involved in these two parts are more connected with the broader online experiences of individuals than that of the geopolitical category (e.g., cyber espionage) (Ibrahim 2016). While the distinctions between these groups are remarkable (as illustrated in Table 1), the TCF is based on the premise that "the perceived world comes as structured information rather than as arbitrary attributes, [and], this condition can be achieved either by the mapping of categories to given attribute structures or by the definition or redefinition of attributes to render a given set of categories appropriately structured" (Rosch 1978, p.28; see also Ibrahim 2016, p.45). For example, there is a reasonably clear pattern that victims of psychosocial cybercrimes such as revenge porn, cyber-harassment, cyber-hate, and cyberbullying, directly and primarily experience a range of similar emotional, psychological, and behavioural health consequences. These consequences include anxiety, self-harm, depression, low self-esteem, and suicidal ideation to varying degrees (Jane 2016b; Watts et al. 2017). However, in addition to the direct psychological costs of psychosocial cybercrimes, coping with these psychologically-based crimes can have indirect financial consequences. For example, costs associated with therapy, residential 
mobility, and time taken off work can drain a victim's financial resources. The same primary and secondary losses do not fit squarely with victims of cyber-fraud (socioeconomic cybercrime), as illustrated in Table 1.

Some researchers (e.g., Tan and David 2017; Whitty and Buchanan 2012, 2016) also suggest that the act of deception involved in fraud can be driven by a non-monetary reward such as a "psychological thrill". Equally, they argue that a financial loss due to cyber-fraud can manifest in the victim physio- logically as distress. These researchers (e.g., Whitty and Buchanan 2016) mainly investigated the experience of romance-scam victims. In romance scams, "criminals pretend to initiate a relationship through online dating sites then defraud their victims of large sums of money" (Whitty and Buchanan 2012, p.181). Thus, their finding regarding the negative psychological consequences for victims may be particularly marked given that romance scams are in the realm of love and friendship and may not be reflective of the experiences of victims of other forms of cyber-fraud (e.g., insurance fraud, and the misappropriation of public funds) without the romance component. As Button and Cross (2017) and Schoepfer et al. (2017) noted, cyber-fraud includes hybrid fraudulent acts such as credit card scam, identity theft, intellectual property crimes, financial/bank fraud, and romance scams. Hence, undoubtedly and primarily, a strong motivation for cyber-fraud and a direct primary loss due to cyber- fraud is money, as shown in Table 1. By implication, cyber-fraud is rooted in socioeconomics. Even though victims are in some cases spiritually manipulated, the spiritual and magical manipulations of victims are rooted in socioeconomic factors and determined by them (Lazarus 2019). But the same cannot be said regarding psychosocial cybercrimes such as revenge porn and cyberbullying, which are fundamentally more expressive or relational than socioeconomic cybercrimes. For example, while the negative experiences of women bloggers (e.g. cyber-stalking, cyberbullying, and rape threats), discussed in Eckert's (2018) article, cannot be described as being primarily rooted in socioeconomics, indisputably, they belong to the psychosocial classification.

It is thus reasonable to suggest that psychosocial cybercrimes such as cyberbullying manifest more through relational processes than socioeconomic cybercrimes such as cyber-fraud. It is also reasonable to agree that the TCF fits with the psychology of gender perceptions and victimisations of crime because the sources of social advantage and disadvantage apply online as they do offline. In fact, "power is not distributed equally online, and this in itself may increase rather than decrease prevailing gender differences in society" (Morahan-Martin 2000a, p.683; see also Eckert 2018). In turn, this article acknowledges here that gender is critical to the analysis of socioeconomic and psychosocial cybercrime categories (with distinctive perpetrator/victim gains and losses mentioned), and this in itself underscores the utilitarian value of the TCF alongside feminist criminology perspectives. Henceforth, this current effort explores the synergy between the feminist perspective and two parts of the TCF to illustrate that while conceptions of gender and crime interact, they also intersect with other categories (e.g., culture and sexuality) to provide additional layers of explanation. In order to achieve this, article pays particular attention to six online crimes ${ }^{5}$ (outlined in Table 2). 
TABLE 2. Operational definitions of the six cybercrime types outlined

\begin{tabular}{|c|c|c|c|}
\hline Cybercrime Types & Category & Operational Definition & Authors \\
\hline Online harassment & Psychosocial & $\begin{array}{l}\text { Online harassment can be defined as the act } \\
\text { of aggressively pressuring, intimidating, } \\
\text { distressing or spread denigrating rumours } \\
\text { about others. }\end{array}$ & Everbach (2018, p.134) \\
\hline Cyberbullying & Psychosocial & $\begin{array}{l}\text { Bullying is an intentional, aggressive } \\
\text { behavior, carried out repeatedly against a } \\
\text { victim, whereas with cyberbullying, the } \\
\text { power imbalance between bully and } \\
\text { victim and the repetitiveness of the } \\
\text { behavior typically involved in traditional } \\
\text { bullying are often missing from the } \\
\text { equation. }\end{array}$ & Cartwright (2016, p.2) \\
\hline Cyber-fraud & Socioeconomic & $\begin{array}{l}\text { Cyber-fraud refers to the computer or/and } \\
\text { internet-mediated acquisition of financial } \\
\text { benefits by false pretense, impersonation, } \\
\text { manipulation, counterfeiting, forgery or } \\
\text { any other fraudulent representation of } \\
\text { facts. }\end{array}$ & Ibrahim $(2016$, p.48) \\
\hline Revenge porn & Psychosocial & $\begin{array}{l}\text { Revenge porn is defined as non-consensual } \\
\text { sharing of sexually explicit images } \\
\text { (including photographs) and/or videos, } \\
\text { with an underlying motivation linked to } \\
\text { revenge. }\end{array}$ & Walker and Sleath $(2017$, p.2) \\
\hline Cyberstalking & Psychosocial & $\begin{array}{l}\text { Cyberstalking or "cyber dating abuse" can be } \\
\text { defined as the use of the internet and other } \\
\text { technological devices to monitor or harass } \\
\text { another person in a threatening way. }\end{array}$ & Marcum et al. (2017, p.375) \\
\hline Digital piracy & Socioeconomic & $\begin{array}{l}\text { While digital piracy involves the illegal } \\
\text { uploading or downloading of computer } \\
\text { files and software, offenders generally } \\
\text { victimise creative artists, and their } \\
\text { respective industries, whose creative } \\
\text { works they acquire without paying for } \\
\text { them. }\end{array}$ & Donner (2016, p.558) \\
\hline
\end{tabular}

\section{Overview of gender gap online}

\subsection{Gendering online harassment (psychosocial category)}

While a person's gender is a product of social constructions, it has real-life consequences (Cook 2016; Everbach 2018; Naegler and Salman 2016) that manifest in the virtual as they do in the real world. The manifestations of these real-life repercussions of gender are less obscured if people's perceptions of digital crimes are framed with the TCF alongside feminist criminology perspectives than with the term "cybercrime" and the binary typologies. The underlying idea is that the motivations, victimisations, and relational processes involved in digital crimes listed in Table 2 do not commonly situate women and men similarly. For example, as regards online harassment (psychosocial 
cybercrime), Lindsay and Krysik's (2012) survey of 342 university students and Finn's (2004) survey of 339 college students support the above assertion regarding the importance of factoring gender into the cybercrime equation. Their studies (both in the United States) found that the perpetrator-victim relational processes were particularly apparent in online harassment because the majority of participants reported that the perpetrators were people known to the victims. Regarding the gender gap in online harassment, Barlett and Coyne's (2014) meta-analysis of 109 studies found that while boys are more likely than girls to commit online harassment in general, girls were more likely to engage in cyber-harassment during adolescence in particular. The underlying assumption is that adolescence in itself is a time of turmoil ${ }^{6}$ (Hazen et al. 2008; Larsen and Ham 1993; Schneider and Csikszentmihalyi 2017) and adolescent children, irrespective of their gender, commonly report more negative conflict with their parents and peers.

However, a few studies, such as those of Marcum et al. (2012) and Holt et al. (2012), suggest that women are more likely than men to harass their peers online. While the above findings indicate that it is unclear whether there are consistent gender trends in online harassment, none of the studies enquired as to whether online harassment (psychosocial cybercrime) is more gendered than socioeconomic cybercrimes, such as cyber- fraud, given the differences between them discussed above. Closely related to online harassment is cyber-bullying. Clear distinctions between cyber- bullying and online harassment (as far as perpetrators and victims are concerned) have not yet been thoroughly made in psychology (Englander et al. 2017). Nonetheless, unlike cyberbullying, online harassment typically lacks a perpetrator- victim power-imbalance structure (Englander et al. 2017).

\subsection{Gendering cyberbullying (psychosocial category)}

Most generalisable research on gender gaps in bullying suggests that boys/men are more likely to be involved in physical bullying (e.g., Beckman et al. 2013; Berger 2007; Smith 2012), whereas girls/women are more involved in verbal, expressive, and relational bullying (e.g., Beckman et al. 2013; Berger 2007). The meta-analysis by Watts et al. (2017) of 54 published articles highlighted that individuals' gender is implicated in leading them to become cyber-bullies or continue to be victims. In a similar vein, various studies of students (Aricak 2009; Cunningham et al. 2015; Kraft and Wang 2010; Schenk and Fremouw 2012) have found that while women were more likely to report involvement as cyber-bullying witnesses, men were more likely to report involvement as perpetrators. Consistent with the above studies, Boulton et al.'s (2012) study of 405 undergraduates in the United Kingdom indicated that women view cyber- bullying, and those who perpetrate it, more negatively than their counterparts (men). Relatedly, Faucher et al.'s (2014) survey of 1925 Canadian university students reported that fewer men than women were cyberbullied by acquaintances and friends.

However, while the above studies portray a fairly clear pattern regarding gender trends in cyber-bullying, they relied exclusively on university students for their studies' samples, and this pattern of data may have influenced the authors' assertions. Their assertions may not be generalisable to other populations, primarily because how researchers produce knowledge is relevant to what the claims are. Youth cultures and the exaggerated 
masculinity inherent in youth groups may have shaped the pattern of their results. Additionally, as some researchers (Donner 2016; James 2010) have observed, while it may be unclear whether there are consistent gender trends in cyber-bullying, the more diffused lifestyles available in cyberspace complicate any gender trends within bullying in the virtual world. "Indeed, greater computer expertise may resolve the power imbalance associated with traditional bullying, conferring greater power unto those who might otherwise lose a school- yard fight or a 'real world' popularity contest" (Cartwright 2016, p.2). While considerations of the higher computer expertise of a victim may or may not change the status quo typically associated with gender trends in traditional bullying, none of the above studies probed whether psychosocial cyber- crimes such as cyber-bullying are more gendered than socioeconomic cybercrimes, such as cyber- fraud, given their dissimilarities through the lens of the TCF, mentioned earlier.

\subsection{Gendering cyber-fraud (socioeconomic category)}

Regarding cyber-fraud, general populations most ordinarily view fraud by any means (online and offline), and by both juvenile and adults, as similarly reprehensible (e.g., Schoepfer et al. 2017). Insights from white-collar crime suggest that most women who embezzled money excuse their fraudulent behaviour through feminine themes (e.g., caregiver role), whereas by contrast most men who embezzled account for their crime through masculine themes, reflecting gender roles and nuances in society (e.g., Zietz 1981). Similarly, Klenowski et al. (2011), who interviewed 40 inmates in the United States, examined how men and women "do gender" when accounting for their crimes in their interview study. They found that offenders draw on gendered themes to align their actions with cultural expectations of masculinity and femininity. For example, qualitative studies found that while Nigerian ${ }^{7}$ men (and boys) predominate in "cybercrime" as perpetrators, most Nigerians involved in "cybercrime" types, in general, are involved in cyberfraud in particular (e.g., Aransiola and Asindemade 2011; Lazarus 2018; Lazarus and Okolorie 2019). Women, how- ever, play subordinate roles, such as the retrieval of fraud proceeds (Lazarus and Okolorie 2019). Ibrahim (2017), who interviewed 17 parents, demonstrated that gender roles involved in cyber-fraud perpetration are reflective of a complex web of familial factors and cultural forces.

Familial and cultural forces socialise men and women as masculine and feminine individuals (Oakley 2018). Cultural expectations of masculinity and femininity perpetuate the domination of men over women (Connell and Messerschmidt 2005, p.832) and in Nigeria, men (and boys) are socialised to be sole bread-winners and the principal head of the household (Ibrahim, 2015; Smith, 2017). Under customary and Islamic types of marriages, some men can marry multiple wives ${ }^{8}$ (Lazarus et al. 2017), which increases their financial responsibilities: "In virtually every arena of Nigerian men's lives, money's value is closely tied to the social work that it does in men's relationships with women" (Smith 2017). Since gender category membership is attached to the cultural expectations and performativity (Connell and Messerschmidt 2005; West and Zimmerman 1987), in this context, "men's cultural positionality in society influences them to be generally more 'desperate' to achieve financial success than women online"- cyber-fraud 
(Ibrahim 2016, p.54).

Based on the preceding insights, I argue that men's hegemonic role in cyber-fraud as perpetrators is the mirror of, and made possible by, women's sub- ordinate position in society. Additionally, I argue that, for many Nigerian cyber-fraudsters, cyber- fraud is a way of demonstrating their masculinity when legitimate means are denied. The critical point here is that cultural factors in Nigeria intersect with gender and cyber-fraud. Through the lens of intersectionality, the value of a cultural context becomes more apparent. While the Nigerian culture, for example, serves as a resource for understanding gender and crime connections, it offers additional layers of explanation.

How such cultural contexts can be used as a resource for understanding gender and crime connections is also exemplified in the connection between music and cyber-fraud. Weitzer and Kubrin's (2009) analysis of rap songs in the United States showed that while masculinity and femininity are central themes in music, artists do not work in a vacuum, and their songs are reflective of the broader gender hierarchy in society (see also Efthymiou and Stavrakakis's 2018 analysis of gender and music in Greece). Similarly, Lazarus's (2018) study, which examined the ways Nigerian cyber-fraudsters are represented in hip-hop music, is revealing (see also Lazarus and Okolorie's 2019 study, which interviewed 40 Nigerian law enforcement officers). These studies (Lazarus 2018; Lazarus and Okolorie 2019) found that while some musicians and cyber-fraudsters are "birds of a feather that flock together", the core aspects of their relationship are based on reciprocal economic benefits and determined by them. "Some musicians are convicted cyberfraudsters or ex-cyber criminals, and some others are beneficiaries of active cybercriminals' fraudulent activities" according to Lazarus (2018, p.71). Of interest is the observation that "fewer women than men glamorised cyber- fraud and cyberfraudsters in their songs" (Lazarus 2018, p.73). The link between cyber-fraud and music reinforces that online and offline lives are inextricably inter- twined. In turn, real bodies and real people are affected ${ }^{9}$ not only according to their gender but also through the prisms of popular culture, which acknowledges the importance of Tynes et al.'s (2016) notion of the digital intersectionality. This article, however, pays more attention to gender and crime connections than other categories, as previously mentioned.

While the above discussions expose the intersectionality of gender, the socioeconomic cyber- crime (i.e., cyber-fraud), familial factors and popular culture, gender may be more of an index factor for victimisation in psychosocial cybercrimes than socioeconomic cybercrimes. For example, in light of the broader experience of fraudulent activities (e.g., in the context of online shopping) in people's lives, socioeconomic victimisations are different from those that are psychosocial, since a majority of people, irrespective of their gender, regularly experience fraudulent sales online (e.g., eBay) (FBI 2010, 2016). Unlike psychosocial cybercrimes, socioeconomic digital crimes are primarily financially motivated victimisations. Equally, this resonates with the view that the primary and secondary consequences of socioeconomic and psychosocial victimisations are qualitatively different, as shown in Table 1 (which challenges the definition of 
the umbrella term, "cybercrime"). While relational processes and dynamics mainly separate socioeconomic cybercrimes (e.g., credit card fraud and digital piracy) from psychosocial digital crimes (e.g., cyber-bullying and revenge porn), the latter is more expressive than the former.

\subsection{Gendering revenge porn (psychosocial category)}

Concerning revenge porn, a summary of the current state of knowledge comes from Walker and Sleath's (2017) review of 82 published studies. ${ }^{10}$ They reported that while four studies, which examined the gender gap among adult populations, explicitly stated that the victimisation rates were higher for men than women, the gender gap was statistically significant in only a few studies (e.g., Priebe and Svedin 2012) (for a fuller analysis, see Walker and Sleath 2017). A careful examination of Priebe and Svedin's (2012) study in Sweden (involving 1,592 men and 1,840 women) perhaps sheds further light on the meaning of the gender gap in question. These authors argue that cultural nuances have double standards for men and women sexual minorities (e.g., homosexual and bisexual), which might have affected the above findings on any gender gap. These researchers (e.g., Priebe and Svedin 2012) revealed that a sexual minority group of men had almost six-fold increased odds of victimisation, whereas for women the increased odds were only twofold compared to their heterosexual counterparts.

Gender and sexuality could be seen as two sides of the same coin: they mutually construct each other. Indeed, sexuality intersects with gender and crime victimisation to offer a deeper explanation. While the legal and cultural contexts of nation states undeniably shape how the experiences of victims vary (Jones 2018), these contexts are critical to our understanding of who is victimised, why, and to what effect. For example, the Nordic nations (e.g., Finland and Sweden) and West African countries (e.g., Ghana and Nigeria) are almost at the opposite ends of the spectrum as far as the social rights of minorities, in general, are concerned (Ibrahim and Komulainen 2016; Rush and Lazarus 2018). The legal and cultural penalties of homosexuality in Sweden are far less severe than those in Nigeria, where, for example, homosexuality can lead to capital punishment in the northern region and 14 years' imprisonment in the southern region. While the lens of intersectionality provides additional layers of explanation, it also resonates with Buist and Lenning's (2016), Cook's (2016) and Ball et al.'s (2018) view that placing non-binary gender nuances as a theoretical starting point for investigating crimes would stimulate a more productive and more complete criminology awakening from slumber.

In this respect, Drouin et al.'s (2013) study on revenge porn in the United States elaborated that victimisation, in general, was most prevalent, in ascending order of significance, among people in committed relationships ( 3 per cent), "no strings attached" relationships (15 per cent), or cheating relationships ( 21 per cent). Based on this evidence, it is conceivable that mainstream cultural norms and values about gender roles and "good" sexual relationships are influential in shaping both the patterns and extent of victimisations. Nonetheless, while the above studies about gender gaps examined revenge porn, none compared psychosocial (e.g., revenge porn) and socioeconomic categories (e.g., cyberfraud and illegal downloading of items). This conceptual article therefore aims to encourage researchers to investigate whether gender is more of an index factor for psychosocial cybercrimes than those which are socioeconomic (in line with the TCF and feminist 
criminology).

\subsection{Gendering cyberstalking (psychosocial category)}

While people perceive stalking through any means (online and offline) as similarly severe (e.g., Garnett-Bower 2017), some researchers have assumed that the men-perpetrator/women-victim structure applies as equally to cyber-stalking as it does to physical stalking (e.g., Purcell et al. 2009). However, like cyberbullying, other central premises are far from straightforward. Notably, Smoker and March (2017) suggested that the boundary between men and women in participating in and experiencing cyber-stalking behaviour is blurred. Some researchers (e.g., Helsper and Whitty 2010; Purcell et al. 2001, 2010) found that women were more likely than men to cyber-stalk their partners covertly. In particular, Helsper and Whitty (2010) surveyed 920 people in the United Kingdom and found that married women were more likely than men to use technology to monitor their partner's behaviour discreetly.

The above researchers (Helsper and Whitty 2010; Purcell et al. 2010) suggest that women (more so than men) use technology as a monitoring "toolbox" to maintain committed relation- ships. In a similar vein, Smoker and March (2017, p.393) concede: "the motivation to attain intimacy through preserving or establishing a relationship may provide women with the drive to conduct IPCS [increased opportunities for intimate partner cyber-stalking]". On the flipside, Marcum et al. (2017) surveyed 890 university students and high- lighted that men were more likely to cyber-stalk and attempt log-ins to their partner's social media accounts. Marcum et al. (2017) explained the men- perpetrator/women-victim structure as implicitly constituting "cyber dating abuse", whereas other researchers (e.g., Helsper and Whitty 2010; Purcell et al. 2001) framed their findings slightly differently, as discussed above.

A closer consideration suggests that Helsper and Whitty (2010) surveyed people primarily over 30 years old (in the United Kingdom), whereas Marcum et al. (2017) surveyed youths under 30 years old (in the United States). If the above findings (Helsper and Whitty 2010; Marcum et al. 2017) are taken as a given, it is conceivable that gender roles and cultural obligations in society (e.g., feminine roles and the social obligations of a married woman to protect her committed relationship delicately) shaped their perceptions and behaviours regarding cyber-stalking. The bottom line here is that age interacts with gender to provide an additional layer of explanation, which acknowledges the value of the lens of intersectionality. Equally, even though the legal and cultural contexts in the United States and the United Kingdom about cyber- stalking vary (Jones 2018), it is reasonable, how- ever, to argue that gender and cultural commitments in the nations where these studies were based offer central explanations. Additionally, while some may perceive cyberstalking as "troubling behaviour" and "dating abuse", others may see it as a "monitory gadget" or a functional behaviour to help maintain a committed relationship. The internet does not exist in a vacuum, and the ways in which online behaviours and attitudes are extensions of offline social processes and relationships 
is also evidenced in the meaning of cyber-stalking. Arguably, this mismatch between these different age groups concerning the meaning of cyber-stalking, however trivial, suggests that, as Sheridan et al. (2016) noted, the meaning of cyberstalking is largely socially constructed. While terms may appear to be objective, they are actually underpinned by value judgements that are rooted in particular cultural assumptions (Ribbens et al. 2011; Stambolis- Ruhstorfer and Saguy 2014).

Indeed, there is no objective viewpoint for the definition of an "immoral" act (Becker [1967] 1997; Reiner 2016). Cyber-stalking, as an action, could be interpreted in a negative or positive light depending on the perceived perpetratorvictim- gender structure. Also, while cyber-stalking may involve "behaviours that are ostensibly routine and harmless" (Sheridan et al. 2016, p.2), some people stalk to some extent even without any malicious intent, given that the boundary between socially acceptable courting and cyber-dating abuse is blurred (Choo et al. 2017). It could be that some people generally indulge in cyber-stalking at some point as a socially acceptable courting act. By implication, a variable minimum number of occurrences for the action to be considered as cyber- stalking may apply differently to each participant, given that its meaning is diffuse and it primarily occurs under the realm of "love" and romance (Marcum et al. 2017). In fact, it is the degree of prior intimacy between the victim and perpetrator that largely influences most people's perceptions of harm in cyber-stalking behaviours (Sheridan et al. 2016). Equally, cultural expectations and norms for romantic relationships offline extend and shape the meaning of cyber-stalking because people generally have diverse opinions as to what exactly constitutes cyberstalking. The above studies high- light the need to understand gender differences in cyber-stalking. Relatedly, gender differences identified in all the above studies (on cyber-stalking, online harassment, cyber-bullying, cyber-fraud, and revenge porn) illuminate that the critical starting points for the analysis of gender and crimes are who is victimised, why and to what effect. Since psychosocial cybercrimes (e.g., cyber-stalking) could be more gendered than socioeconomic ones (e.g., cyberfraud), the meaning of "cybercrime" is problematic, as previously argued. It is noteworthy that cyber-stalking (psychosocial cybercrime) has not been compared with socioeconomic crimes (e.g., digital piracy) to better understand their differences in the light of the TCF (and the feminist epistemology of crime).

\subsection{A comparison of three digital crimes (case study) framed with mainstream criminology theory}

A recent study (Donner 2016), which compares the forms of digital crimes (hacking, online harassment, and digital piracy), is framed with Gottfredson and Hirschi's (1990) General Theory of Crime. It con- tends that men were more likely to engage in online offending and that this gender gap was reasonably consistent across the board. In particular, this study found that men were more likely to engage in online harassment (psychosocial) and digital piracy (such as illegal downloads of items, i.e., socioeconomic), irrespective of self-control level, whereas "higher immersion into the cyber-environment resulted in men and women having similar rates of digital piracy" (i.e., a socioeconomic cybercrime) (Donner 2016, p.570), which suggests that perhaps socioeconomic cybercrime is less gendered than online harassment (psychosocial cybercrime) if viewed from the lens of the TCF. 
Accordingly, this study's findings could have been a little more clearly and directly expressed had a more gender-sensitive framework been applied in place of a mainstream criminology lens. For instance, Donner (2016, p.571) acknowledged, "the findings revealed that, regardless of self-control level, men had higher rates [than women] of online offending almost across the board, which is inconsistent with the theory. Thus, it appears that gender may be more useful in explaining cybercrime than self-control, although self-control is more important for low self-control individuals, as it eliminated the gender difference in digital piracy". The author then recommends that "future researchers should consider utilising a bond-based measure of self-control, which would be more theoretically consistent with the revised version of the theory" (Donner 2016, p.572). These obscurities in reporting research findings nevertheless echo the suggestion that theories may be supportive or obstructive to the researchers' analytic capacity when they have more faith in the correctness of the theories than in the authenticity of their data (Greenwald et al. 1986). This therefore reinforces the notion that mainstream criminology theories may not be a "toolbox" for cyber or digital criminology inquiries, as in Rimer's (1997) term, as theology is for followers. By building on the extant literature, I argue here that who is victimised, why, and to what effect do not apply in the same way to socioeconomic cybercrimes as they do to psychosocial cybercrimes. Therefore, this article, framed with the TCF along- side the feminist epistemology of crime, advocates the centrality of gender as a theoretical starting point for the examination of the gender gap between psychosocial and socioeconomic cybercrime types.

Prompted by the above primary limitation, this article proposes that persisting with the umbrella term "cybercrime", the binary typologies, and some mainstream criminology theories, does not help us to understand how structured gender relations might retain their efficacy in online contexts because a person cannot be online without being offline. The lens of "cybercrime", as an umbrella term, and the binary typologies obscure the manifestation of gender cultures and nuances in multiple areas of social lives. These typologies and theories under- mine a more critical examination of gender issues concerning a wide range of digital crimes. Framed with the TCF, this article has demonstrated that psychosocial cybercrimes could be more gendered than those which are socioeconomic. For example, as previously mentioned, Donner's (2016) paper demonstrated that digital piracy (socioeconomic cybercrime) was perceived similarly across sexes. On the flipside, as regards a range of psychosocial crimes such as cyberbullying (e.g., Cunningham et al. 2015), revenge porn (e.g., Walker and Sleath 2017), cyber-stalking (e.g., Marcum et al. 2017), and online harassment (e.g., Barlett and Coyne 2014), numerous studies demonstrate that who is victimised, why, and to what effect are the critical entry points to the analysis of gender and crimes. It is plausible, therefore, to argue that the psychosocial category is more gendered than the socioeconomic category (e.g., digital piracy and cyber-fraud). Arguably, the TCF provides support for continuing to expand our analysis of gender issues in cyber criminology, as well as a more refined theoretical perspective for grouping a wide spectrum of cybercrime types above. Thus, as Eagly (2016) and Wood and Eagly (2010) illuminate, rather than discounting, the existence of sex-related differences, such differences and similarities are reflections of cultural nuances and norms of social interaction. 


\section{Conclusion}

While this article has underscored the utilitarian value of the TCF, it aligns it with feminist criminology perspectives. It accentuates that it is of the utmost importance for the umbrella term "cybercrime" and most mainstream criminology theories to be revisited, redefined, and reconstructed because they have huge consequences. They have, for example, obscured the centrality of gender as a theoretical starting point for examining a multitude of digital crimes in academia. Such theoretical and methodological oversights in research, in turn, have real-life repercussions. A likely consequence of these omissions is that many corporations and government agencies may not fully recognise the importance of gender and crime connections in their responses to many forms of digital crime.

I recommend that researchers on "cyber criminology" or "digital criminology" should unconditionally take on board the feminist criminology agenda, given that many digital crimes may not possess the same features as the traditional ones from which they have emerged. Indeed, a greater computer expertise on the part of women (and girls) may realign the prevailing men/women unequal power relation associated with perpetrator/victim traditional crimes. Mere proficiency in ICT and immersion in cyberenvironments may reshape pat- terns of offending and victimisation for crimes that depend primarily on ICT skills.

Fundamentally, this paper is a theoretical endeavour that advocates the centrality of gender as a conceptual starting point for investigations in cyber criminology. Building on previous works that have critiqued mainstream criminology (e.g., Cook 2016; hooks [1984] 2000), this article argues that more has to be done to wake criminology from its "androcentric slumber". Accordingly, this paper has attempted to stimulate contemporary scholarly endeavours to be more alert or sensitive to gender issues. It has attempted to stimulate scholars to situate the feminist epistemology of crime at the core of criminology enquiries, because generations after generations of scholars who are unaware of feminist criminology as students concomitantly teach their students mainstream theories at the expense of feminist approaches, as discussed above. Consequently, only the marginal voices whose endeavours fit squarely with the aims and scopes of marginal publication venues (often with "low or average impact factors") tend to challenge the orthodoxy of mainstream criminology.

As long as the term "cybercrime", the binary typologies, and most mainstream criminology theories are taken as a given in cyber criminology research (and influence researchers the way theology does believers), windows of opportunities necessary to advance our understanding of gender and a range of digital crimes will continue to be limited. Additionally, this article has not only demonstrated that structured gender relations retain their efficacy in online contexts, but it has also illustrated what gender is and that women and men do interact with other categories (e.g., age and sexuality) to influence the experiences of victims of digital crimes. Thus, the article has not only benefited from the lens of TCF but also from an additional lens. Simply put, by employing the lens of digital intersectionality, it has considered other categories of social (dis)advantages to answer the question: do structured gender relations retain their efficacy in online contexts? 
While this paper has benefited from the advancement of the TCF, the TCF itself is, however, not immune to limitations. Mainly, the TCF is some- what simplistic. Given that the apparent boundaries between TCF's categories are blurred, they could be seen as a loose grouping of cybercrime types. A complex web of hybrid forms of crimes on the internet exposes the TCF's weakness. For example, cyberbullying could eventually lead to cyber- extortion, or hacktivists exposing stolen personal data from police officers, as a political protest could have psychosocial and geopolitical consequences at the same time (as shown in Table 1). Although the TCF has flaws, it has useful contributions in spite of them. It has attempted to move gender analysis of digital crimes "from margin to centre". We will accomplish more, and quicker, if we consider this current endeavour as an avenue to situate the feminist perspectives at the core of cyber criminology enquiries. Future research is needed to strengthen the synergy between the TCF and the feminist epistemology of crime.

\section{Notes}

1. While there are many examinations of girls/women and crime that are not feminist, there are men who are feminist criminologists, and there are many women in criminology who are not feminist (Sharp 2015).

2. However, some mainstream theorists have acknowledged the importance of incorporating feminist approaches into criminology as a field of study (Broidy and Agnew 1997).

3. Social (dis)advantage - inequality in the central and value things people are able to be or do (Dean and Platt 2016).

4. However, the legal and cultural contexts vary across nations (Jones 2018).

5. These six online crimes outlined resonate with the original formulation of the Tripartite Cybercrime Framework (TCF).

6. It is noteworthy that the turmoil associated with adolescence may vary across different measures and social contexts (Schneider and Csikszentmihalyi 2017).

7. Listed in the prevalence of cybercrime perpetrators, Nigeria, the United Kingdom, and the United States (in ascending order of significance) are at the top of the FBI's (2010) "league table". However, a critical examination has pointed out that the statistics the FBI relied upon to inform the current state of cybercrime perpetrators across nations, even when they represent the underlying reality, are socially and selectively constructed - the FBI's statistics, therefore, cannot (or should not)directly speak for themselves (Ibrahim 2016, pp.50-52).

8. Even men's adulterous undertakings are culturally seen as an additional layer of prestige (Smith 2017).

9. In Nigeria, for example, "most cybercriminals involved in stealing panties for money rituals are exclusively involved in stealing women's panties, sometimes at gun/knife points" (Lazarus 2019, p.10).

References

$=$

$=$

Adebanjo, A.T., 2015. Culture, morality and the law: Nigeria's anti-gay law in perspective. Internationaljournal of discrimination and the law, 15 (4), 256-270.

Agboola, C. and Rabe, M., 2018.

Intersectionality and crime: reflections from female ex-inmates in South Africa. Acta 
criminologica: Southern African journal of criminology, 31 (1),

$1-18$.

Al IzKi, F. And WeIR, G.R., 2015.

Gender impact on information security in the Arab world. In: International conference on global security, safety, and sustainability (pp. 200-207).

Cham: Springer.

Aransiola, J.O. and Asindemade,

S.O., 2011. Understanding cybercrime perpetrators and the strategies they employ in Nigeria. Cyberpsychology, behavior, and social networking, 14

(12), 759-763.

AricaK, M.T., 2009. Psychiatric

symptomatology as a predictor of cyberbullying among university students. Eurasian journal of education research, 34, 167-184.

BAE, S.M., 2017. The influence of strain factors, social control factors, self-control and computer use on adolescent cyber delinquency: Korean National Panel Study. Children and youth services review, 78, 74-80.

Ball, M., Lenning, E. And Buist, C.L.,

2018. Queer criminology. London: Routledge.

Barlett, C. and Coyne, S.M., 2014. A

meta-analysis of sex differences in cyber-bullying behavior: the moderating role of age. Aggressive behavior, 40 (5), 474-488.

BAYM, N.K. AND Boyd, D.,2012.

Socially mediated publicness: an

introduction. Journal of broadcasting \& electronic media, 56 (3), 320-329.

BECKER, H., [1967]1997. Outsiders:

studies in sociology of deviance. New York: Simon and Schuster Ltd.

Beckman, L., Hagquist, C. AND

Hellström, L., 2013. Discrepant

gender patterns for cyberbullying and traditional bullying - an analysis of

Swedish adolescent data. Computers in human behavior, 29 (5),1896-1903.

BERgER, K.S., 2007. Update on

bullying at school: science forgotten?

Developmental review, 27 (1), 90-126.

Bidgoli, M. and Grossklags, J., 2016.

End user cybercrime reporting: what we know and what we can do to improve it. In: IEEE

International Conference on Cybercrime and Computer Forensic (ICCCF),

Vancouver, BC, Canada, (pp. 1-6).

BoAкyе, K.E., 2013. Correlates and predictors of juvenile delinquency in Ghana. International journal of comparative and applied criminal justice, 37 (4), 257-278.

Boulton, M., Lloyd, J., Down, J. And

MarX, H., 2012. Predicting undergraduates' self-reported engagement in traditional and cyberbullying from attitudes.

Cyberpsychology, behavior, and social networking, 15 (3), 141-147.

Braithwaite, A., 2014. "Seriously, get out": feminists on the forums and the war (craft) on women. New media \& society, 16 (5), 703-718.

Braithwaite, J., 1989. Crime, shame,

and reintegration. Cambridge, UK: Cambridge University Press.

Broidy, L. And Agnew, R., 1997.

Gender and crime: a general strain theory perspective. Journal of research in crime and 
delinquency, 34(3),

275-306.

Buist, C., AND Lenning, E., 2015.

Queer criminology. New York: Routledge.

Burgess-Proctor, A., 2006.

Intersections of race, class, gender, and crime: future directions for feminist

criminology. Feminist criminology, 1(1), 27-47.

Button, M. And Cross, C., 2017.

Cyber frauds, scams and their victims. London: Routledge.

Cartwright, B.E., 2016.

Cyberbullying and cyber law. In: IEEE International Conference onCybercrime and Computer Forensic (ICCCF), Vancouver, BC, Canada, (pp. 1-7).

Chen, P., Kokbayashi, E., Vazsonyi, A.

AND SHARP, S., 2010. A culturally nuanced test of Gottfredson and Hirschi's "General Theory": dimensionality and generalizability in Japan and the United States.

International criminal justice review, 20 (2), 112-131.

Choo, K.K.R., Eterovic-Soric, B., Ashman, H. and Mubarak, S., 2017.

Stalking the stalkers - detecting and deterring stalking behaviours using technology: a review. Computers \& security, 70, 278-289.

Citron, D.K., 2014. Hate crimes in cyberspace. London: Harvard University Press.

Connell, R.W. and Messerschmidt, J.,

2005. Hegemonic masculinity:

rethinking the concept. Gender and society, 19, 829-859.

Cook, K.J., 2016. Has criminology awakened from its "androcentric slumber"? Feminist criminology, 11 (4), 334-353.

Cunningham, C.E., Chen, Y.,

Vaillancourt, T., Rimas, H., Deal, K., Cunningham, L. J. and Ratcliffe, J.,

2015. Modeling the anti-cyberbullying preferences of university students: adaptive choice-based conjoint analysis. Aggressive behavior, 41 (1), $369-385$.

Daly, K. And Chesney-Lind, M., 1988.

Feminism and criminology. Justice quarterly, 5, 497-538.

Dean, H. and Platt, L., 2016. Social

advantage and disadvantage. Oxford: Oxford University Press.

Donner, C.M., 2016. The gender gap and cybercrime: an examination of college students' online offending.

Victims \& offenders, 11 (4), 556-577.

Donner, C.M., Jennings, W.G. And

BANFIELD, J., 2015. The general nature of online and off-line offending among college students. Social science computer review, 33 (6), 663-679.

Drouin, M., Vogel, K.N., Surbey, A.

AND STILLS, J.R., 2013. Let's talk about sexting, baby: computer-mediated sexual behaviors among young adults. Computers in human behavior, 29 (5), A25-A30.

Eagly, A.H., 2016. IV. Has the

psychology of women stopped playing handmaiden to social values?

Feminism \& psychology, 26 (3),

282-291.

Eckert, S., 2018. Fighting for

recognition: online abuse of women bloggers in Germany, Switzerland, the United 
Kingdom, and the United States. New media \& society, 20 (4),

1282-1302.

EKLUND, L., 2011. Doing gender in cyberspace: the performance of gender by female World of Warcraft players. Convergence, 17 (3), 323-342.

Englander, E., Donnerstein, E., Kowalski, R., Lin, C.A. and Parti, K., 2017. Defining cyberbullying.

Pediatrics, 140, S148-S151.

Efthymiou, A. and Stavrakakis, H., 2018. Rap in Greece: Gendered

configurations of power in-between the rhymes. Journal of Greek Media \& Culture, 4 (2), 205-222.

Everbach, T., 2018. "'I Realized It

Was About Them . . . Not Me': Women Sports Journalists and Harassment.” In

Mediating Misogyny: Gender, Technology, and Harassment edited by Jacqueline Ryan Vickery and Tracy Everbach, 131-150. Cham, Switzerland: Palgrave Macmillan.

FAucher, C., Jackson, M. And CAssidy,

W., 2014. Cyberbullying among university students: gendered experiences, impacts, and perspectives. Education research international.

Retrieved from: https://www.hindawi. com/journals/edri/2014/698545/abs/ [11

November 2017].

FBI, 2010. Internet

crime complaint centre. Retrieved from: https://pdf.ic3.gov/2010_IC3Report.pdf [9 September 2017].

FBI, 2016. Internet crime schemes. Available at: https://www.ic3.gov/

crimeschemes.aspx\#item-13 [28

January 2018].

FINN, J., 2004. A survey of online harassment at a university campus. Journal of interpersonal violence, 19 (4), 468-483.

Flavin, J., 2001. Feminism for the mainstream criminologist: an invitation. Journal of criminal justice, 29 (4), 271-285.

Fogiel-Bijaoui, S., 2016. The

cosmopolitan future: a feminist approach. Laws, 5 (3), 34.

FREUD, S., [1927]1991. Civilization, society and religions: group psychology and the analysis of the ego, future of an illusion and civilization and its discontents. New York:

Penguin Books Ltd.

GARnEtT-Bower, C.I., 2017. Juveniles

and cyberstalking: public perception of offender dangerousness. Thesis (PhD). Alliant International University.

GEIs, G., 2000. On the absence of self-control as the basis for a general theory of crime: a critique. Theoretical criminology, 4 (1), 35-53.

Gordon, S. AND Ford, R., 2006. Onthe

definition and classification of cybercrime. Journal in computer virology, 2 (1), 13-20.

Gottrredson, M. and Hirschi, T.,

1990. A general theory of crime. Stanford, CA: Stanford University Press.

Greenwald, A., Pratkanis, A, Leippe,

M. AND BAUMGARDNER, M., 1986. Under what conditions does theory obstruct research progress?

Psychological review, 93, 216-229.

Hazen, E., Schlozman, S. and Beresin, 
E., 2008. Adolescent psychological.

Pediatrics in review, 29 (5), 161.

Helsper, E.J. And Whitty, M.T., 2010.

Netiquette within married couples: agreement about acceptable online behavior and surveillance between partners. Computers in human behavior, 26 (5), 916-926.

Hill, J.B. and Marion, N.E., 2016.

Presidential rhetoric and cybercrime: tangible and symbolic policy statements. Criminology, crim.justice, law \& society, 17 (2), 1-17.

Holt, T.J., Bossler, A.M. and May,

D.C., 2012. Low self-control, deviant peer associations, and juvenile cyberdeviance. American journal of criminal justice, 37 (3), 1-18.

Hooks, B., [1984]2000. Feminist

theory: from margin to center. New York: Pluto Press.

Hutchings, A. And Chua, Y., 2017.

Gendering cybercrime. In: Holt, T.J. ed. Cybercrime through an interdisciplinary lens (pp. 167188). New York: Routledge.

IBrahim, S., 2015. A binary model of broken home: parental death-divorce hypothesis of male juvenile

delinquency in Nigeria and Ghana In: Maxwell, S.R. and Blair, S.L. eds

Contemporary perspectives in family research, Vol. 9 (pp. 311-340). New York: Emerald Group Publishing Limited.

Iвrahim, S., 2016. Social and contextual taxonomy of cybercrime: socioeconomic theory of Nigerian cybercriminals. International journal of law, crime and justice, 47, 44-57.

IBRAHIM, S., 2017. Causes of

socioeconomic cybercrime in Nigeria. In: IEEE International Conference on Cybercrime and Computer Forensic (ICCCF), Vancouver, BC, Canada, (pp. 1-9).

Ibrahim, S. and Komulainen, S., 2016.

Physical punishment in Ghana and

Finland: criminological, sociocultural, human rights and child protection implications.

International journal of human rights and constitutional studies, 4 (1), 54-74.

JaishanKar, K., 2007. Cyber

criminology: evolving a novel discipline with a new journal. International journal of cyber criminology, 1(1), 1-6.

JAISHANKAR, K., 2011. Expanding cyber criminology with an avant-garde anthology (Introduction). Boca Raton, Florida: CRC Press, Taylor and Francis Group.

JAMES, A., 2010. School bullying. Research briefing. Downloaded from: www.nspcc.org.uk/inform, 26, 2012.

JAne, E.A., 2016a. Online misogyny and feminist digilantism. Continuum, 30 (3), 284-297.

JAne, E.A., 2016b. Misogyny online: ashort (and brutish) history. London: Sage.

Jegede, A.E., Elegbeleye, A.O.,

Olowookere, E.I. and Olorunyomi,

B.R., 2016. Gendered alternative to cyber fraud participation: an assessment of technological driven crime in Lagos State, Nigeria. Gender and behaviour, 14 (3), 7672 7692.

Jones, M.L., 2018. Ctrl Z: the right to be forgotten. New York: NYU Press.

Kirillova, E.A., Kurbanov, R.A., Svechnikova, N.V., Zul'fugarzade,

T.E.D. AND ZENIN, S.S., 2017.

Problems of fighting crimes on the internet. Journal of advanced research in law and 
economics, 8 (3), 849-856.

Klenowski, P.M., Copes, H. And

Muluins, C. W., 2011. Gender,

identity, and accounts: how white collar offenders do gender when making sense of their crimes. Justice quarterly, 28 (1), 46-69.

Kraft, E. And Wang, J., 2010. An

exploratory study of the cyberbullying and cyberstalking experiences and factors related to victimization of students at a public liberal arts college. International journal of technoethics, 1

(4), 74-91.

LARSON, R. AND HAM, M., 1993. Stress

and "stormy and stress" in early adolescence: the relationship of negative events with dyphoric affect.

Developmental psychology, 29

(1),130-140.

Lavee, E. and Benjamin, O., 2017.

Between social rights and human rights: Israeli mothers' right to be protected from poverty and

prostitution. Journal of comparative family studies, 48 (3), 315-326.

LAZARus, S., 2018. Birds of a feather flock together: the Nigerian cyber

fraudsters (Yahoo boys) and hip hop artists. Criminology, criminal justice, law \& society, 19 (2), 63-81.

LAzarus, S., 2019. Where is the

money? The intersectionality of the spirit world and the acquisition of wealth. Religions, $10(3), 146,1-20$.

Lazarus, S., Rush, M., Dibiana, E.T. and Monks, C.P., 2017. Gendered penalties of divorce on remarriage in Nigeria: a qualitative study. Journal of comparative family studies, 48 (3),

351-366.

Lazarus, S. and Uzoma OKolorie, G., 2019. The bifurcation of Nigerian cybercriminals: narratives of the Economic and Financial Crimes Commission (EFCC) agents. Telematics and Informatics, p.1-14.

LindSAY, M. AND KRYSIK, J., 2012.

Online harassment among college students: a replication incorporating new internet trends. Information, communication \& society, 15(5), $703-719$.

LYNCH, M.J., 2016. Acknowledging female victims of green crimes: environmental exposure of women to industrial pollutants. Feminist criminology, 13 (4), 404-427.

Maldonado-Molina, M.M., Piquero, A.R., Jennings, W.G., Bird, H. and

Canino, G., 2009. Trajectories of delinquency among Puerto Rican children and adolescents at two sites. Journal of research in crime and delinquency, 46, 144-181.

Marcum, C.D., Higgins, G.E. And

Nicholson, J., 2017. I'm watching you: cyberstalking behaviors of university students in romantic relationships. American journal of criminal justice, 42 (2), $373-388$.

Marcum, C.D., Higgins, G.E.,

Freiburger, T.L. AND RicketTS, M.L.,

2012. Battle of the sexes: an examination of male and female cyber bullying. International journal of cyber criminology, 6 (1), 904-911. 
McGerty, L.J., 2000. "Nobody lives only in cyberspace": gendered subjectivities and domestic use of the internet. CyberPsychology \& behavior, 3 (5), 895-899.

McGuire, M. And Dowling, S., 2013.

Cybercrime: a review of the evidence. Retrieved from: https://www.gov.uk/

government/uploads/system/uploads/ attachment_data/file/246749/horr75- summary.pdf [28

September 2017].

Morahan-Martin, J., 2000a. Women

and the internet: promise and perils. CyberPsychology \& behavior, 3 (5) 683-691.

Morahan-Martin, J., 2000b. The

gender gap in internet use: why men use the internet more than women. CyberPsychology \& behavior, 1 (1),

3-10.

Mumporeze, N. and Prieler, M., 2017.

Gender digital divide in Rwanda: a qualitative analysis of socioeconomic factors. Telematics and informatics, 34 (7), 1285-1293.

NaEgler, L. And Salman, S., 2016.

Cultural criminology and gender consciousness: moving feminist theory from margin to center.

Feminist criminology, 11 (4),

354-374.

NÄsi, M., OKSANEN, A., KeIPI, T. AND

RÄsÄNEN, P., 2015. Cybercrime victimization among young people: amulti-nation study. Journal of

Scandinavian studies in criminology and crime prevention, 16 (2),

203-210.

National Crime Agency, 2017.

Cybercrime. Available at: http://www.nationalcrimeagency. gov.uk/crime-threats/cyber-crime [7 July 2017].

Newburn, T., 2016. Social

disadvantage: crime and punishment. In: Dean, H. and Platt, L. eds. Social advantage and disadvantage

(pp. 322-340). Oxford: Oxford University Press.

Norton by Symantec, 2015. What is

cybercrime? Retrieved from: http://nz.norton.com/cybercrime- definition [26 July 2016].

OAKLeY, A., 2018. From here to maternity (reissue): becoming a mother. Croydon: Policy Press.

Ojanen, T.T., Boonmongkon, P., Samakkeekarom, R., Samoh, N.,

Cholratana, M. and Guadamuz, T.E.,

2015. Connections between online harassment and offline violence among youth in central Thailand. Child abuse \& neglect, 44, 159-169.

Potter, H., 2015. Intersectionality and criminology: disrupting and revolutionizing studies of crime. New York, NY: Routledge.

Powell, A., Stratton, G. and

Cameron, R., 2018. Digital criminology: crime and justice in digital society. London: Routledge.

Priebe, G. and Svedin, C.G.,2012.

Online or off-line victimisation and psychological well-being: a comparison of sexualminority and

heterosexual youth. European child \& adolescent psychiatry, 21 (10),

569-582.

Purcell, R., Pathe, M. and Mullen,

P.E., 2001. A study of women who stalk. American journal of psychiatry, 158 (12), 
$2056-2060$.

Purcell, R., Pathe, M. and Mullen, P.,

2009. Gender differences in stalking behavior among juveniles. Journal of

forensic psychiatry and psychology, 21 (4), 555-568.

Purcell, R., Pathe, M. and Mullen,

P.E., 2010. Gender differences in

stalking behaviour among juveniles. Journal of forensic psychiatry \& psychology,

21 (4), 555-e568.

Available at: http://doi.org/10.1080/ 14789940903572035.

REINER, R., 2016. Crime, the mystery of the common-sense concept. New York: John Wiley \& Sons.

RibBens McCarthy, J. And Edwards,

R., 2011. Key concepts in family studies. London: Sage Publications.

Richardson, S.V.A. and Gilmour, N.,

2015. Cyber crime and national security: a New Zealand perspective. European review of organised crime, 1 (1), 51-70.

Rimer, B., 1997. Perspectives on intrapersonal theories of health

behavior. In: Glanz, K., Lewis, F. and Rimer, B. eds. Health behaviour and health

education: theory, research and practice (pp. 139-147). Jossey-Bass, San Francisco,

CA.

Rokven, J.J., WeIJTERs, G.,

Beerthuizen, M. G. van der LaAn,

A.M., 2018. Juvenile delinquency in the virtual world: similarities and differences between cyber-enabled, cyber-dependent and offline

delinquents in the Netherlands. International journal of cyber criminology, 12 (1), $27-46$.

Rosch, E., 1978. Principles of categorization. In: Rosch, E. and Lloyd, B.B. eds. Cognition and categorization (pp. 27-48). Hillsdale, NJ: Lawrence Erlbaum Associates.

Rosenbach E. ANd BeLK, R., 2012.U.S.

cybersecurity: the current threat and future challenges. In: Burns, N. and Price, J. eds.

Securing cyberspace - a new domain for national security.

Washington, DC: The Aspen Institute.

Rush, M. and Lazarus, S., 2018.

"Troubling" chastisement: a comparative historical analysis of child punishment in Ghana and Ireland.

Sociological research online, 23 (1),

177-196.

Sabillon, R., Cavaller, V., Cano, J.

and Serra-Ruiz, J., 2016.

Cybercriminals, cyberattacks and cybercrime. In: IEEE International Conference on

Cybercrime and Computer Forensic (ICCCF),

Vancouver, BC, Canada, (pp. 1-9).

SABON, L.C., 2016. Force, fraud, and coercion - what do they mean? A study of victimization experiences in a new destination Latino Sex Trafficking Network. Feminist criminology, 13 (5), 456-476.

Schenk, A.M. and Fremouw, W.J.,

2012. Prevalence, psychological impact, and coping of cyberbully victims among college students.

Journal of school violence, 11, 21-37. 
Schiebinger, L., 2000. Has feminism changed science? Signs: journal of women in culture and society, 25 (4), 1171-1175.

SCHNeider, B. And Csikszentminalyi,

M., 2017. Conditions for optimal development in adolescence: an experiential approach. In: Conditions for optimal development in adolescence (pp. 122-124). New York: Psychology Press.

Schoepfer, A., Baglivio, M. And

Schwartz, J., 2017. Juvenile hybrid white-collar delinquency: an empirical examination of various frauds.

Criminology, criminal justice law and society, 18 (2), 21-38.

SHARP, F.S., 2015. Feminist

criminology and gender studies.

International encyclopedia of thesocial \& behavioral sciences, 2 (8),912-917.

Sheridan, L., Scott, A. J. And Nixon,

K., 2016. Police officer perceptions of harassment in England and Scotland. Legal and criminological psychology, 21 (1), 1-14.

Sherman, R.C., End, C., Kraan, E., Cole, A., Campbell, J., Birchmeier, Z.

and Klausner, J., 2000. The internet gender gap among college students: forgotten but not gone? Cyberpsychology, Behavior, and Social Networking, 3 (5), 885-894.

Sмiтн, D.J., 2017. To be a man is not a one-day job: masculinity, money, and intimacy in Nigeria. Chicago: University of Chicago Press.

Sмiтн, P.K., 2012. Cyberbullying and cyber aggression. In: Jimerson, S.R., Nickerson, A.B., Mayer, M.J. and

Furlong, M.J. eds. Handbook of school violence and school safety: international research and practice,

2nd ed. (pp. 93-103). New York: Routledge.

SMOKer, M. AND March, E., 2017.

Predicting perpetration of intimate

partner cyberstalking: gender and the dark tetrad. Computers in human behavior, 72, 390-396.

Stambolis-Ruhstorfer, M.and Saguy,

A.C., 2014. How to describe it? Why the term coming out means different things in the United States and France. Sociological forum, 29 (4), 808-829.

TAN, H.K. AND DAVID, Y., 2017.

Preying on lonely hearts: a systematic deconstruction of an internet romance scammer's online lover persona.

Journal of modern languages, 23 (1),

$28-40$.

Tynes, B.M., SchuschKe, J. AND

Noble, S.U., 2016. Digital

intersectionality theory and the black matter movement. In: Noble, S.U. and Tynes, B.M., eds. The intersectional internet: race, sex, class, and culture online. Berlin: Peter Lang International Academic Publishers.

VAsilescu, B., CAPIluppi, A. AND

Serebrenik, A., 2012. Gender,

representation and online participation: a quantitative study of stackoverflow. In: IEEE International Conference on Social Informatics (pp.332-338).

IEEE.

Walker, K. and Sleath, E., 2017. A

systematic review of the current knowledge regarding revenge pornography and non-consensual sharing of sexually explicit media. Aggression and violent behavior, 36, 9-24. 
Watts, L.K., Wagner, J., Velasquez,

B. And Behrens, P.I., 2017.

Cyberbullying in higher education: a literature review. Computers in human behavior, 69 , 268-274.

Weitzer, R. ANd Kubrin, C.E., 2009.

Misogyny in rap music: a content analysis of prevalence and meanings. Men and masculinities, 12 (1), 3-29.

West C. and Zimmerman, D.H., 1987.

Doing gender. In: Fenstermaker, S. and West, C. eds. Doing gender, doing difference (pp. 3-24). New York:

Routledge.

Whitty, M.T. and Buchanan, T., 2012.The online romance scam: a serious cybercrime. CyberPsychology, behavior, and social networking, 15 (3),181-183.

WhitTy, M.T. and Buchanan, T., 2016.

The online dating romance scam: the psychological impact on victims - both financial and non-financial.

Criminology \& criminal justice, 16 (2),

176-194.

Wood, W. and Eagly, A.H., 2010.Gender. In: Fiske, S.T., Gilbert, D.T. and Lindzey, G. eds. Handbook of social psychology (Vol. 1) 5th ed. (pp. 629-667). Hoboken, NJ: Wiley.

YAR, M., 2017. Online crime. In: Pontell, H. ed. Oxford research encyclopedia of criminology: criminology \& criminal justice. Oxford: Oxford University Press.

ZIETZ, D., 1981. Women who embezzle or defraud: a study of convicted felons. New York: Praeger.

ZuPAN, L.L., 1986. Gender-related differences in correctional officers' perceptions and attitudes. Journal of criminal justice, 14 (4),

349-361. 